\title{
Low loss TiO2 channel waveguides
}

Hegeman, I., Dijkstra, M., García-Blanco, S.

I. Hegeman, M. Dijkstra, S. M. García-Blanco, "Low loss TiO2 channel waveguides," Proc. SPIE 11283, Integrated Optics: Devices, Materials, and Technologies XXIV, 112830C (25 February 2020); doi: 10.1117/12.2543003 


\title{
Low loss $\mathrm{TiO}_{2}$ channel waveguides \\ I. Hegeman ${ }^{1}$, M. Dijkstra ${ }^{1}$, S.M. García-Blanco ${ }^{1}$ \\ ${ }^{1}$ Optical Sciences Group, MESA + Institute for Nanotechnology, University of Twente, P.O. Box 217, 7500 AE Enschede, The Netherlands
}

\begin{abstract}
$\mathrm{TiO}_{2}$ is gaining interest as material for integrated photonics, due to its high refractive index, large transparency window and high non-linear refractive index. Its low phonon energy makes it attractive for the realization of active devices in the visible frequency range. In this work, we optimize different process steps of the fabrication of low $\operatorname{loss} \mathrm{TiO}_{2}$ channel waveguides. The $\mathrm{TiO}_{2}$ layers are deposited by DC sputter deposition, using a mixed $\mathrm{Ar} / \mathrm{O}_{2}$ plasma. Removing the hysteresis in the deposition process, results in reduced propagation losses of the $\mathrm{TiO}_{2}$ films (estimated less than $1.5 \mathrm{~dB} / \mathrm{cm}$ at $632 \mathrm{~nm}$ wavelength). An E-beam lithography process is utilized to reduce the sidewall roughness of the waveguides. Different reactive gasses are compared to optimize the reactive ion etching recipe. $\mathrm{BCl}_{3}$ in combination with $\mathrm{HBr}$ shows to be most beneficial for etching $\mathrm{TiO}_{2}$ with high selectivity towards negative E-beam resist. A selectivity of 2.7 for $\mathrm{TiO}_{2}$ over the E-beam resist is obtained. The performance of a $\mathrm{TiO}_{2}$ a channel waveguide fabricated with the process before and after optimization is compared. The waveguide fabricated using the non-optimized process exhibited losses of $7.82 \pm 0.52 \mathrm{~dB} / \mathrm{cm}$ at a wavelength of $632.8 \mathrm{~nm}$, after applying an $\mathrm{SiO}_{2}$ cladding. After process optimization, $5.08 \pm 0.65 \mathrm{~dB} / \mathrm{cm}$ were obtained, without an $\mathrm{SiO}_{2}$ cladding.
\end{abstract}

Keywords: $\mathrm{TiO}_{2}$, channel waveguide, Sputter deposition, hysteresis, UV contact lithography, E-beam lithography, reactive ion etching, propagation losses.

\section{INTRODUCTION}

$\mathrm{TiO}_{2}$ possesses a high refractive index of 2.3-2.4 [1,2] and a large transparency window from the visible to infrared wavelength range due to its high bandgap of $3 \mathrm{eV}$ [3]. These material properties make $\mathrm{TiO}_{2}$ promising for integrated photonic circuits with a small footprint. The possibility to dope $\mathrm{TiO}_{2}$ with, for example, rare earth ions or Si [4-7] makes $\mathrm{TiO}_{2}$ promising for active on chip devices. $\mathrm{TiO}_{2}$ exhibits a high non-linear refractive index, resulting in the demonstration of third harmonic generation [8], supercontinuum generation [9], spectral broadening [10] and four-wave mixing [11]. The negative thermo-optic coefficient [12] allows for the realization of athermal devices [13], by combining $\mathrm{TiO}_{2}$ with, for example, $\mathrm{Si}_{3} \mathrm{~N}_{4}[14,15]$ or silicon $[16,17]$. The high refractive index has allowed the demonstration of high efficiency in waveguide enhanced Raman spectroscopy $[18,19]$.

Low propagation losses need, however, to be achieved in order for $\mathrm{TiO}_{2}$ waveguides to find real applications. Current results in literature report channel waveguide losses down to $9.7 \mathrm{~dB} / \mathrm{cm}$ at a $632.8 \mathrm{~nm}$ [1] and $4 \mathrm{~dB} / \mathrm{cm}$ at $1550 \mathrm{~nm}$ [2], using conventional fabrication techniques, i.e. deposition, lithography and etching. A lift-off process has shown losses as low as $7.5 \mathrm{~dB} / \mathrm{cm}$ at $632.8 \mathrm{~nm}$ and $1.2 \mathrm{~dB} / \mathrm{cm}$ at $1550 \mathrm{~nm}[20]$.

$\mathrm{TiO}_{2}$ is commonly deposited by reactive sputter deposition [1,2,11,21-23]. The structure of the deposited film is very dependent on the oxygen partial pressure during the process. Unfortunately, hysteresis in the process prevents in many cases to reach the optimum deposition parameters. In this work we experimentally demonstrate the influence of the total gas flow and target size during the sputtering process, as predicted by the Berg model [24]. A method is shown to optimize the sputter deposition process for low-loss films.

The etching of $\mathrm{TiO}_{2}$ waveguides is usually performed using reactive ion etching with fluoride containing gasses [1,2,11,25], often combined with $\mathrm{Ar}$ or $\mathrm{O}_{2}$. Furthermore, these studies report the use of a $\mathrm{Cr}$ of $\mathrm{Al}$ hard mask, made by E-beam lithography using positive resist followed by lift-off. The use of negative E-beam resist can result in a much simpler process. However, this requires high etch selectivity of $\mathrm{TiO}_{2}$ towards resist. Studies have been performed on the properties of different reactive gasses, such as $\mathrm{CF}_{4}[26-28], \mathrm{SF}_{6}[28,29], \mathrm{Cl}_{2}[29,30]$ and $\mathrm{BCl}_{3}$ [31]. In this work, we compare systematically the influence of $\mathrm{SF}_{6}, \mathrm{CHF}_{3}, \mathrm{HBr}, \mathrm{BCl}_{3}$ and $\mathrm{Cl}_{2}$ as reactive gas and optimize the etching recipe.

\section{PROCESS OPTIMIZATION}

The fabrication of $\mathrm{TiO}_{2}$ is performed in three process steps. First a $\mathrm{TiO}_{2}$ layer is deposited by means of reactive sputter deposition. The deposition is followed by a lithography and etching step. Each of the three fabrication steps is optimized in order to reduce the propagation losses of the resulting $\mathrm{TiO}_{2}$ channel waveguide. 


\section{Sputter deposition}

Thin $\mathrm{TiO}_{2}$ films are deposited by means of DC reactive sputter deposition from a 4 inch $99.999 \%$ pure Ti target in the TCOater in the MESA+ cleanroom. The deposition was performed at a constant pressure of $6 \cdot 10^{-3} \mathrm{mbar}$, a target to substrate distance of $176 \mathrm{~mm}$, a constant DC power of $500 \mathrm{~W}$ and a temperature of the substrate between $20-30{ }^{\circ} \mathrm{C}$. A Si wafer with an $8 \mu \mathrm{m}$ thick layer of thermal $\mathrm{SiO}_{2}$ is used as substrate. The optimum oxygen flow is determined by studying the bias curve, which shows the voltage between the target and ground, depending on the oxygen flow into the reactor.

As the oxygen flow increases, the target gets more oxidized. For $\mathrm{TiO}_{2}$ the secondary electron yield is lower than for Ti [32]. When applying a constant power to the target, the current drops and, consequently, the bias voltage increases, as the target oxidizes. The bias curve is related to the oxidation state of the target. The measurement of the bias curve starts at an $\mathrm{O}_{2}$ flow of $0 \mathrm{sccm}$, which is then increased. After reaching the top of the bias curve, the same curve is measured for decreasing $\mathrm{O}_{2}$ flow. It is experimentally observed that depositions at the left (low $\mathrm{O}_{2}$ flow) side of the curve result in non-stoichiometric layers, which show no optical guiding. Depositions performed at the right side of the curve show stoichiometric optically guiding layers. However, the morphology depends on the $\mathrm{O}_{2}$ flow. The best optically guiding layers are deposited in the region of optically guiding layers, but with as low $\mathrm{O}_{2}$ flow as possible [33]
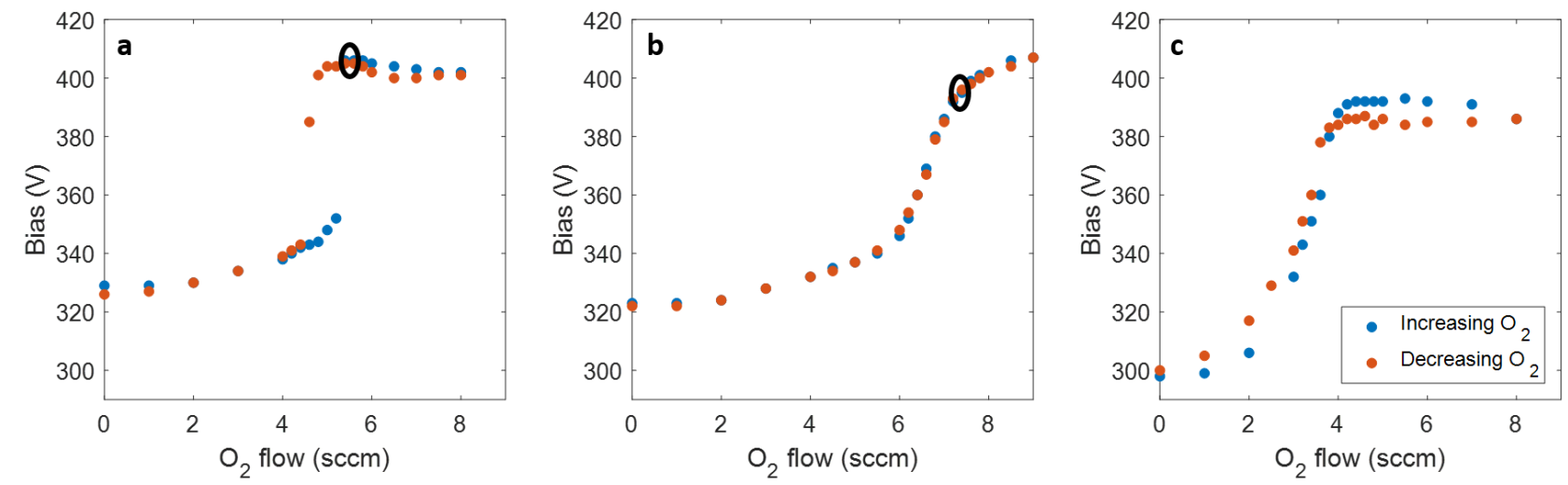

Figure 1. Bias curve for (a) $40 \mathrm{sccm}$ Ar flow and a 4" Ti target, (b) $80 \mathrm{sccm}$ Ar flow and a 4" Ti target and (c) $40 \mathrm{sccm}$ Ar flow and a 2" Ti target.

The measured bias curves are shown in figure 1. In case of figure 1a, a 4" Ti target and a constant Ar flow of 40 sccm are used and hysteresis is observed in the bias curve. Any deposition performed in the hysteresis part of the curve, in this case between 4.4 and $5.4 \mathrm{sccm}$ of $\mathrm{O}_{2}$ flow, will not be stable. In this case the best optical layers are obtained at point indicated with the black ellipse, which corresponds to an $\mathrm{O}_{2}$ flow of $5.6 \mathrm{sccm}$. Propagation of the resulting slab mode is shown in figure 2a, which does show reasonable optical guiding, but significant propagation losses. In order to perform depositions at lower a point closer to the metallic regime, the hysteresis needs to be taken out of the process. This can be done by increasing the Ar flow into the reactor or by reducing the target size [34]. This is shown in figure $1 \mathrm{~b}$ for an Ar flow of $80 \mathrm{sccm}$ with a 4 " Ti target and in figure 1c for an Ar flow of $40 \mathrm{sccm}$ with a 2" Ti target. The case of a higher Ar flow with the bigger target is used to deposit a second layer, since this case will give a higher deposition rate compared to the case of a 2" target. Figure $2 \mathrm{~b}$ shows the propagation of a slab mode at a wavelength of $632.8 \mathrm{~nm}$, through a $\mathrm{TiO}_{2}$ layer deposited with $80 \mathrm{sccm} \mathrm{Ar}$ and $7.3 \mathrm{sccm} \mathrm{O}_{2}$ flow, which corresponds to the marked point in figure 1b. It is observed that the propagation losses are significantly lower, compared to the layer shown in figure $2 \mathrm{a}$. 

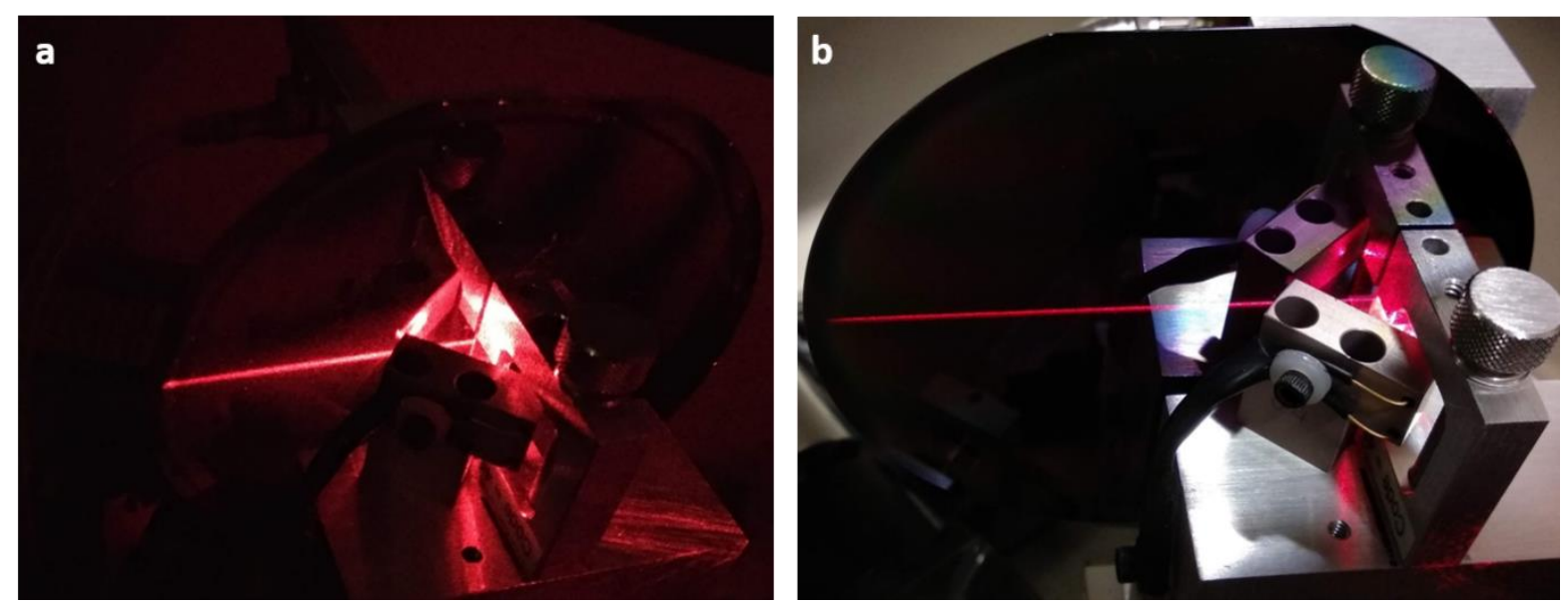

Figure 2. Propagation of slab modes at a wavelength of $632.8 \mathrm{~nm}$ in $\mathrm{TiO}_{2}$ layers. For both images the coupling point is located at the right side of the image and the mode propagates to the left. (a) Propagation through a $\mathrm{TiO}_{2}$ layer deposited with $40 \mathrm{sccm} \mathrm{Ar}$ and $5.6 \mathrm{sccm} \mathrm{O}$. (b) Propagation through a $\mathrm{TiO}_{2}$ deposited with $80 \mathrm{sccm} \mathrm{Ar}$ and $7.3 \mathrm{sccm} \mathrm{O}$.

The origin of the hysteresis can be explained using the Berg model [24]. Figure 3a shows the reactive gas pressure in the reactor as a function of the reactive gas $\left(\mathrm{O}_{2}\right)$ flow into the chamber. It must be noted that these figures are reproduced based on the Berg model and do not match with the bias curves shown in figure 1. They do however help in qualitative understanding of the process. Figure 3a shows 3 different possible reactive gas pressures for a single value of the reactive gas flow, for reactive gas flows between approximately 1.8 and $2.9 \mathrm{sccm}$ of reactive gas flow. As a result, there are three different compound fractions possible of both the target and the deposited layer for these values of reactive gas flow, shown in figure $3 \mathrm{~b}$. As explained before, the compound fraction is related to the secondary electron yield and thereby the obtained current and voltage at a certain power. When the reactive gas flow is increased, the compound fraction of the target increases gradually, until about $2.9 \mathrm{sccm}$. When further increasing the reactive gas flow, a jump in the compound fraction is observed, following the black dotted line. When decreasing the reactive gas flow again, a jump occurs at lower reactive gas flow. The process configuration in between the two black lines cannot be obtained, without removing the hysteresis.
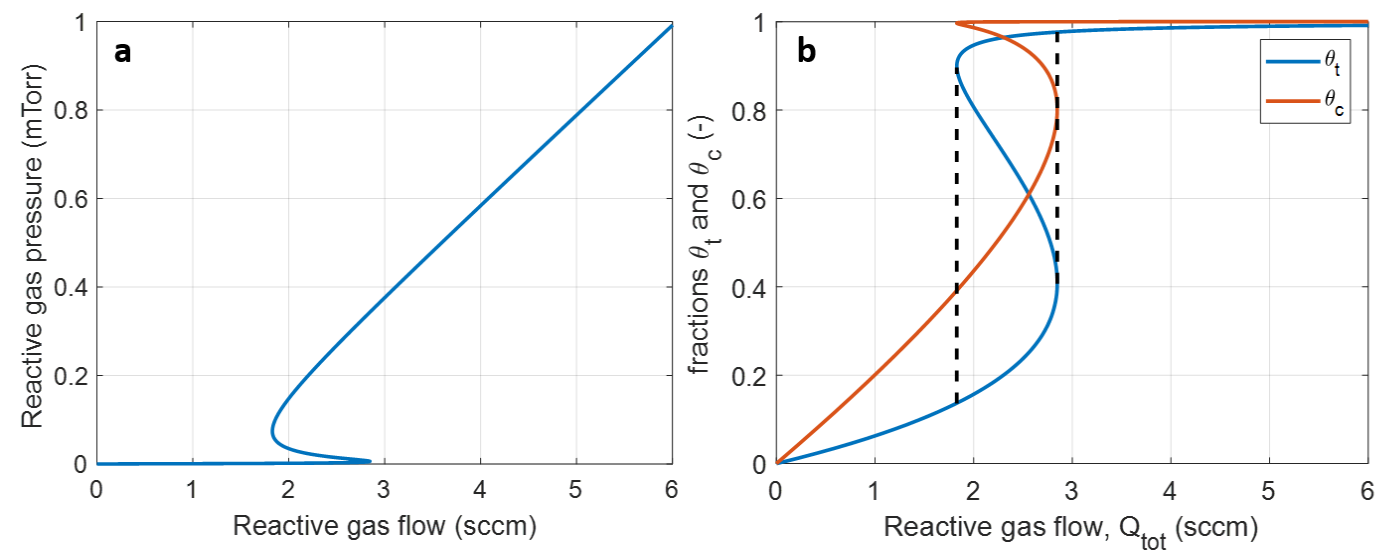

Figure 3. (a) reactive gas pressure vs reactive gas flow and (b) the compound fraction at both the wafer $\left(\theta_{\mathrm{c}}\right)$ and the target $\left(\theta_{\mathrm{t}}\right)$, both reproduced from the Berg model [24].

The hysteresis is caused by gettering of the reactive gas at the collection area (i.e. the wafer). When starting at a reactive gas pressure of zero and increasing the reactive gas pressure, the amount of reactive gas consumption by the collection area increases rapidly due to the increased availability of the reactive gas, as shown by the yellow line in figure 4 .

However, the target gets oxidized, causing the sputter yield to drop, which causes a lower deposition rate. As a result the reactive gas consumption at the collection area decreases again. When this effect is bigger than the reactive gas 
consumption of the target or the pump, hysteresis will be observed, since at a single reactive gas flow, there are multiple solutions for the reactive gas pressure. As shown in figure $1 \mathrm{~b}$, the hysteresis can be taken out of the process by increasing the gas flow (both $\mathrm{Ar}$ and $\mathrm{O}_{2}$ ). Since for the actual deposition we work with a constant pressure, an increased gas flow will result in an increased flow towards the pump. When the slope of the pump line (figure 4a) is higher than the maximum negative slope of the collection area, no hysteresis will occur. Another possibility is reducing the target size, as is used in figure 1c. Reducing the target size reduces the deposition rate and thereby the getter effect of the collection area, which by the same reasoning takes out the hysteresis. Both methods for reducing the hysteresis in the reactive sputtering process were both predicted by the Berg model [34].

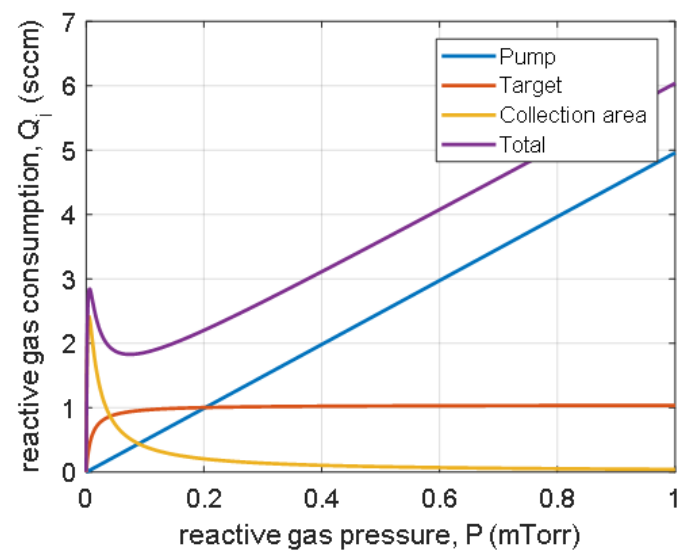

Figure 4. reactive gas consumption by the pump, target and collection area for varying reactive gas pressure, reproduced from the Berg

\section{E-beam lithography} model [24].

An origin of propagation losses in waveguide is the sidewall roughness. During the lithography process, roughness can occur in the resist patterns. When etching the structures, the roughness in the resist can be transferred to the waveguide structures. In order to reduce the sidewall roughness, high resolution resist patterns are required. An E-beam lithography (EBL) recipe is developed for negative resist (AR-N 7520.18). After dehydration of the substrate, an HMDS layer is spun at $4000 \mathrm{rpm}$ for $45 \mathrm{~s}$, to promote adhesion to the substrate. The resist is spun at $1500 \mathrm{rpm}$ for $180 \mathrm{~s}$, to get a homogeneous resist layer of $650-700 \mathrm{~nm}$ thick, followed by a baking step at $80^{\circ} \mathrm{C}$ for 1 minute. A conductive coating (AR-PC 5091) is spun on top of the resist at $2000 \mathrm{rpm}$ for $45 \mathrm{~s}$, followed by a baking step at $50{ }^{\circ} \mathrm{C}$ for 2 minutes. The conductive coating is to prevent charging during the EBL process. Exposure is performed with the Raith EBPG 5150 in the MESA+ cleanroom, with a beam current of $80 \mathrm{nA}$, an acceleration voltage of $100 \mathrm{kV}$ and a dose of $800 \mu \mathrm{C} / \mathrm{cm}^{2}$. Development is performed in AR 300-47 developer for $60 \mathrm{~s}$.
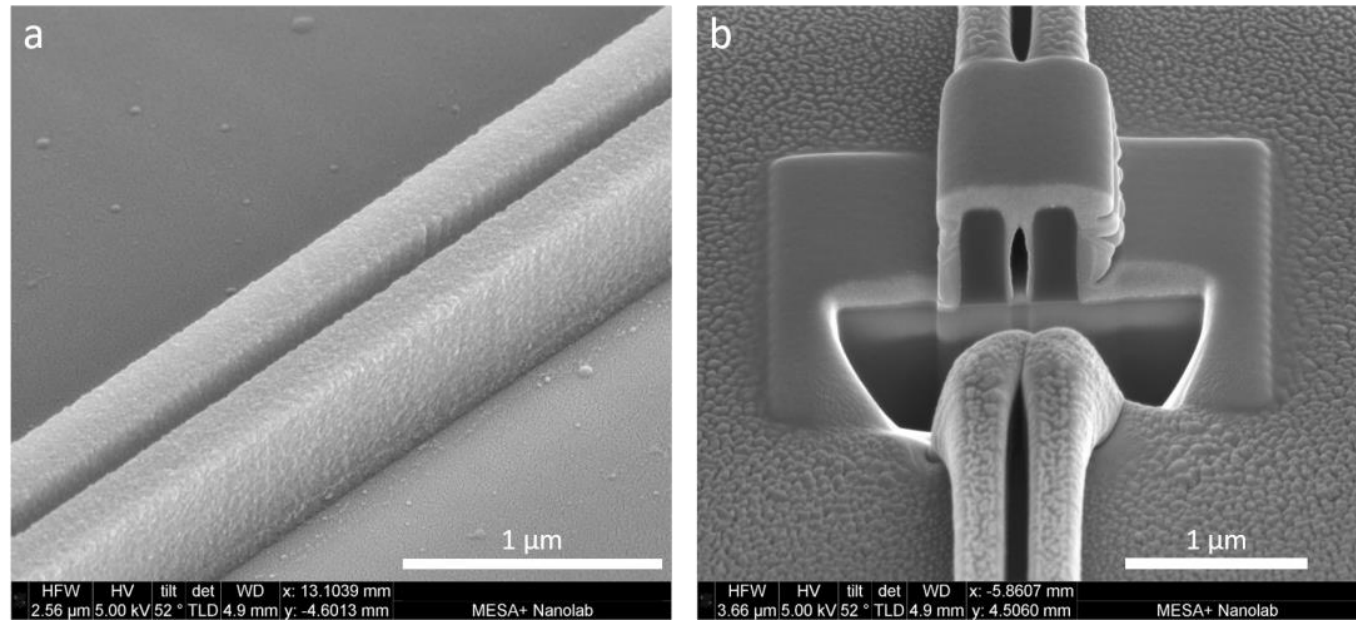

Figure 5. (a) Sideview of negative EBL patterns. (b) Cross-section of negative EBL patterns covered with a thin Pt layer to prevent rounding during the FIB milling process. 
Figure 5a shows a sideview of a typical resist pattern. The observe roughness is partially caused by the applied SEM coating, which is required to prevent charging during imaging. To observe the gap of the structure, a cross-section is made by using a focused ion beam (FIB), as is shown in figure 5b. Prior to the FIB milling a Pt coating is deposited, to prevent rounding of the structure due to the FIB milling. The patterns show low amounts of roughness and structures with a width down to $300 \mathrm{~nm}$ and gaps down to $150 \mathrm{~nm}$ can be obtained.

\section{Reactive ion etching}

In order to obtain waveguide structures with straight sidewalls, a reactive ion etching recipe has been developed to etch $\mathrm{TiO}_{2}$ with high selectivity towards photoresist. Before optimizing the etching recipe, the different available chemistries are compared. The etching is performed with the Plasma Pro 100 Cobra in the MESA+ cleanroom. The general process settings are summarized in table 1.

\begin{tabular}{c|c|c|c|c}
$\begin{array}{c}\text { Pressure } \\
(\mathbf{m T o r r})\end{array}$ & $\begin{array}{c}\text { Time } \\
(\mathbf{m m}: \mathbf{s s})\end{array}$ & $\begin{array}{c}\text { HF power } \\
(\mathbf{W})\end{array}$ & $\begin{array}{c}\text { ICP power } \\
(\mathbf{W})\end{array}$ & $\begin{array}{c}\text { Temperature } \\
\left({ }^{\circ} \mathbf{C}\right)\end{array}$ \\
\hline \hline 10 & $01: 00$ & 20 & 1500 & 10 \\
& \multicolumn{2}{|c|}{ Table 1. Etch parameters }
\end{tabular}

The etch rate of the negative EBL resist, the $\mathrm{SiO}_{2}$ substrate and the $\mathrm{TiO}_{2}$ film are compared for etching in $\mathrm{SF}_{6}, \mathrm{CHF}_{3}$ $\mathrm{HBr}, \mathrm{Cl}_{2}$ and $\mathrm{BCl}_{3}$, which are the available gasses in the used etching machine. As shown in table 2, $\mathrm{SF}_{6}$ shows the highest etching rate of $\mathrm{TiO}_{2}$, however poor selectivity towards both resist and $\mathrm{SiO}_{2}$. $\mathrm{CHF}_{3}$ etches much slower, but with slightly better selectivity towards the resist. $\mathrm{HBr}$ and $\mathrm{Cl}_{2}$ show hardly any etching of the $\mathrm{TiO}_{2}$ layer. $\mathrm{BCl}_{3}$ gives a relatively high etch rate, and a electivity higher than 1 towards the resist and 3 towards the $\mathrm{SiO}_{2}$, which makes $\mathrm{BCl}_{3}$ the reactive gas to perform the $\mathrm{TiO}_{2}$ etching. Another advantage is the much lower vapor pressure of $\mathrm{TiCl}_{4}[35,36]$ compared to $\mathrm{TiF}_{4}$, which reduces the chance of redeposition, which might lead to roughness and consequently scattering losses.

\begin{tabular}{c||c|c|c|c|c} 
& $\mathbf{S F}_{\mathbf{6}}$ & $\mathbf{C H F}_{\mathbf{3}}$ & $\mathbf{H B r}$ & $\mathbf{C l}_{\mathbf{2}}$ & $\mathbf{B C l}_{\mathbf{3}}$ \\
\hline \hline Resist & 175 & 36 & 20 & 77 & 34 \\
\hline \hline $\mathbf{S i O}_{2}$ & 71 & 73 & 10 & $\sim 0^{*}$ & 15 \\
\hline \hline $\mathbf{T i O}_{2}$ & 55 & 15 & $\sim 0 *$ & 4 & 45
\end{tabular}

Table 2. Etch rates for different reactive gasses with a flow of $25 \mathrm{sccm}$

*no etching measured within measurement limit

First optimization steps are performed by starting with a $25 \mathrm{BCl}_{3}$ flow and adding $\mathrm{Ar}$ and $\mathrm{O}_{2}$, as shown in figure $6 \mathrm{a}$ and b respectively. The etching rate increases slightly by adding Ar, which can be explained by the increased physical component of the etching. However the selectivity does not increase. When adding $\mathrm{O}_{2}$, the etching rate of the resist increases drastically and the etch rate of $\mathrm{TiO}_{2}$ and $\mathrm{SiO}_{2}$ decreases, so adding $\mathrm{O}_{2}$ to the etching process is not favorable. The influence of the HF power is shown in figure $6 c$, showing increased etching rates for higher HF powers. Increasing the HF power, increases the acceleration of the plasma, resulting in higher impact energy of the ions. The reduced

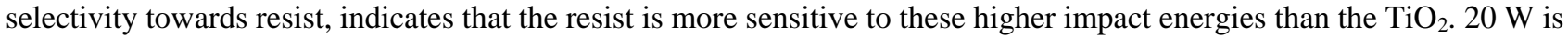
used as a minimum HF power, since lower powers are not stable. Figure $6 \mathrm{~d}$ shows a decreasing etch rate, but higher selectivity for higher pressures. For lower pressures, the mean free path of the ions increases, causing less collisions of the ions when accelerated towards the substrate. As a result the impact energy will be higher, which again affects the resist more than the $\mathrm{TiO}_{2}$. However, a lower pressure will result in a more directional plasma, which is required for straight sidewalls of the waveguide structure. Since a pressure of 5 mTorr still results in a selectivity higher than 1, this pressure is chosen to continue the process. Figure 6e shows the slightly increased etching rate of $\mathrm{TiO}_{2}$ for increased $\mathrm{BCl}_{3}$ flow, which is caused by the increased amount of ionized reactive gas. The selectivity is also slightly increased, since the EBL resist and the $\mathrm{SiO}_{2}$ are not affected by the chemical component of the etching. At last $\mathrm{HBr}$ is added to the etching process. In $\mathrm{Al}_{2} \mathrm{O}_{3}$ processes $\mathrm{BCl}_{3}$ is also used, but in combination with $\mathrm{HBr}$ [37], which makes the addition of $\mathrm{HBr}$ a promising step. As shown in figure 6e, the etch rates of $\mathrm{TiO}_{2}$ and $\mathrm{SiO}_{2}$ are hardly affected, but the etch rate of the EBL resist decreases drastically, resulting in a selectivity of about 2.7. 

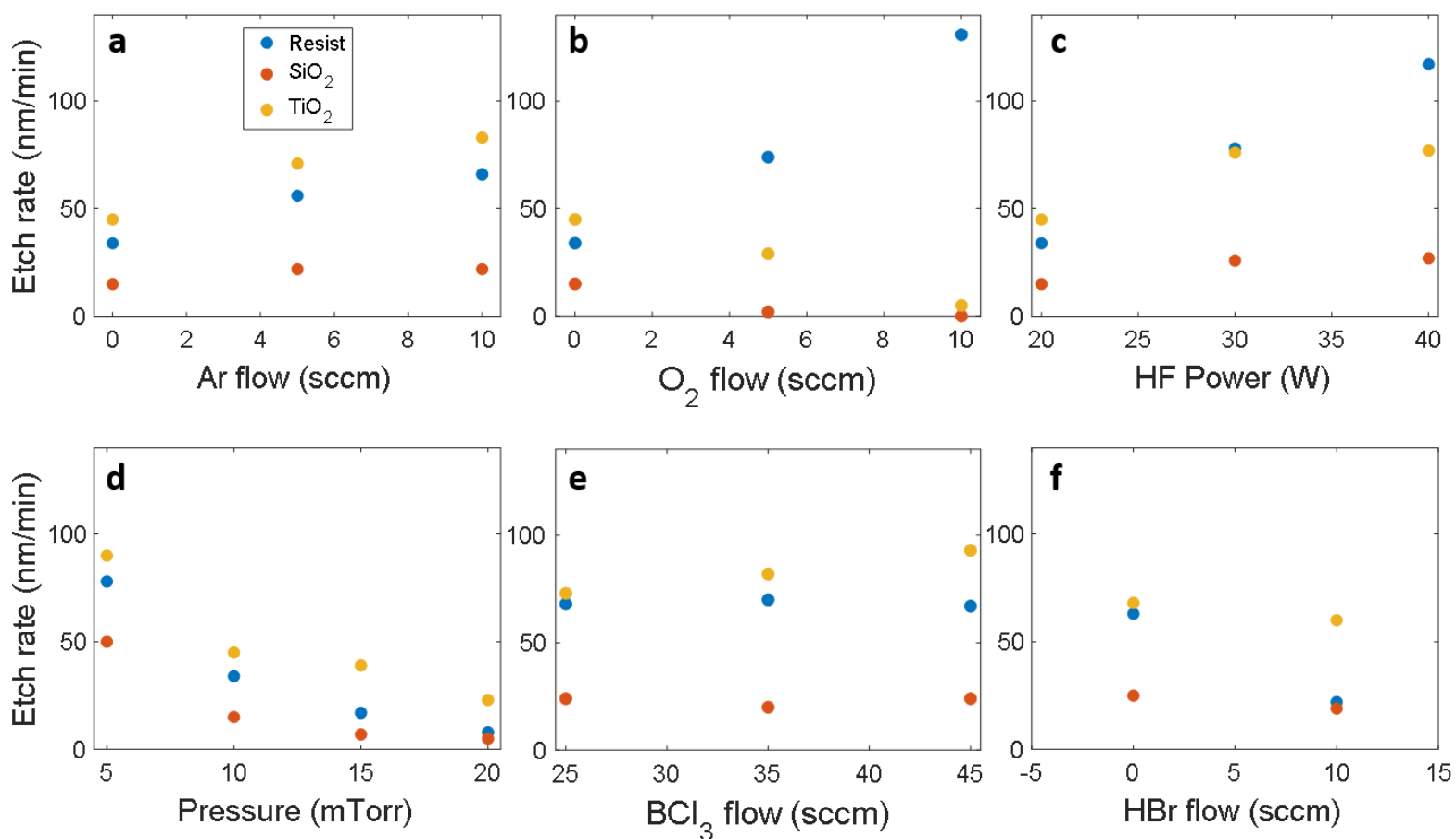

Figure 6. Etching rates of negative EBL resist, $\mathrm{SiO}_{2}$ and $\mathrm{TiO}_{2}$ for varying (a) Ar flow, (b) $\mathrm{O}_{2}$ flow, (c) $\mathrm{HF}$ power and (d) pressure. Other settings during the etching process are as stated in table 1, except for the HF power in figure (c) and the pressure in figure (d).

For the final etching recipe that is used for waveguide fabrication, the following settings are used: pressure of $5 \mathrm{mTorr}$, HF power of $20 \mathrm{~W}$, ICP power of $1500 \mathrm{~W}$, temperature of $10{ }^{\circ} \mathrm{C}$, a BCl 3 flow of $45 \mathrm{sccm}$ and an $\mathrm{HBr}$ flow of $10 \mathrm{sccm}$. This recipe resulted in etching rates of the EBL resist, $\mathrm{SiO}_{2}$ and $\mathrm{TiO}_{2}$ of 29,31 and $81 \mathrm{~nm} / \mathrm{min}$ respectively, which shows a selectivity of $\mathrm{TiO}_{2}$ towards the EBL resist of 2.8 and 2.6 towards $\mathrm{SiO}_{2}$.

\section{WAVEGUIDE FABRICATION}

Two different waveguides are compared in terms of propagation losses. Waveguide $\mathrm{A}$ is fabricated prior to optimization of the fabrication process [33]. Waveguide $\mathrm{B}$ is fabricated after the optimization process. Waveguide $\mathrm{A}$ is fabricated using a $\mathrm{TiO}_{2}$ layer deposited at a configuration similar to figure 1a. Patterning is performed using a photo contact lithography process, followed by a reactive ion etching step. Waveguide $\mathrm{B}$ is fabricated from a $\mathrm{TiO}_{2}$ layer deposited at a point like the indicated point in figure 1b. The patterning is performed using EBL followed by an etching step using the optimized recipe.

\section{Deposition}

The $\mathrm{TiO}_{2}$ film used for waveguide $\mathrm{A}$ is $140 \mathrm{~nm}$ thick and is deposited with an $\mathrm{Ar}$ flow of $35.4 \mathrm{sccm}$ and an $\mathrm{O}_{2}$ flow of $4.6 \mathrm{sccm}$. This corresponds to a deposition at a point similar to the indicated point in figure 1a. The other process parameters were a pressure of $6 \cdot 10^{-3} \mathrm{mbar}$, temperature between $20-30{ }^{\circ} \mathrm{C}$, DC power of $500 \mathrm{~W}$, 4 " Ti target of $99.999 \%$ purity and a target to substrate distance of $176 \mathrm{~mm}$. For waveguide B a $224 \mathrm{~nm}$ thick layer is deposited using an $\mathrm{O}_{2}$ flow of $7.3 \mathrm{sccm}$ and an Ar flow of $80 \mathrm{sccm}$ is used, the other settings stayed the same. The substrate consists of a 4" Si wafer with an $8 \mu \mathrm{m}$ thick thermal oxide layer.

\section{Lithography}

For waveguide A, photo contact lithography is performed using a $1.7 \mu \mathrm{m}$ thick photoresist layer (Olin Oir 907.17), applied by spincoating using the standard recipe in the MESA+ cleanroom. Waveguide B is made using EBL. The spinning, exposure and development are performed as stated before in the E-beam lithography section. Waveguide A has a width of $1 \mu \mathrm{m}$ and waveguide B has a width of $1.2 \mu \mathrm{m}$. 


\section{Etching}

The etching for waveguide $\mathrm{A}$ is performed using an etching recipe based on $\mathrm{SF}_{6}$ with the following settings, a pressure of 10 mTorr, temperature of $10^{\circ} \mathrm{C}$, ICP power of $1500 \mathrm{~W}, \mathrm{CCP}$ power of $20 \mathrm{~W}$, and $\mathrm{SF}_{6}, \mathrm{O}_{2}$ and Ar flow rates of 25, 6 and $5 \mathrm{sccm}$ respectively. The etching of waveguide $\mathrm{B}$ is performed using an etching recipe based on $\mathrm{BCl}_{3}$, as stated in before in the reactive ion etching section.

\section{Cladding}

Waveguide A is covered by a $1 \mu \mathrm{m}$ thick $\mathrm{SiO}_{2}$ cladding, which is deposited by e-beam evaporation from a $99,999 \%$ pure $\mathrm{SiO}_{2}$ target in the BAK600 in the MESA+ cleanroom. The target to substrate distance is kept at $15 \mathrm{~cm}$. Evaporation was chosen in order to keep the sample at room temperature to prevent crystallization of the $\mathrm{TiO}_{2}$. The settings for the evaporations were a beam current of $200 \mathrm{~mA}$ and a base pressure of $6 \cdot 10^{-6} \mathrm{mbar}$.

Waveguide B is uncladded. Attempts were made to deposit the same cladding on top of waveguide B, as was used for waveguide A. In the case of waveguide B, the cladding cracked, making the device unsuitable for characterization. A measurement of this structure before applying the top cladding is used for comparison with waveguide A.

\section{WAVEGUIDE CHARACTERIZATION}

Light is coupled into the waveguides by fiber coupling, using a HeNe laser with a wavelength of $632.8 \mathrm{~nm}$. A top view image is taken with a Point Grey monochrome camera (BFLY-U3-23S6M-C) to image the scattering losses. Figure 7 shows the images for waveguide A and B. A trace of the spiral is made to obtain the intensity as a function of the propagated distances, which is used to fit an exponential decay to the data, in order to obtain the propagation losses.
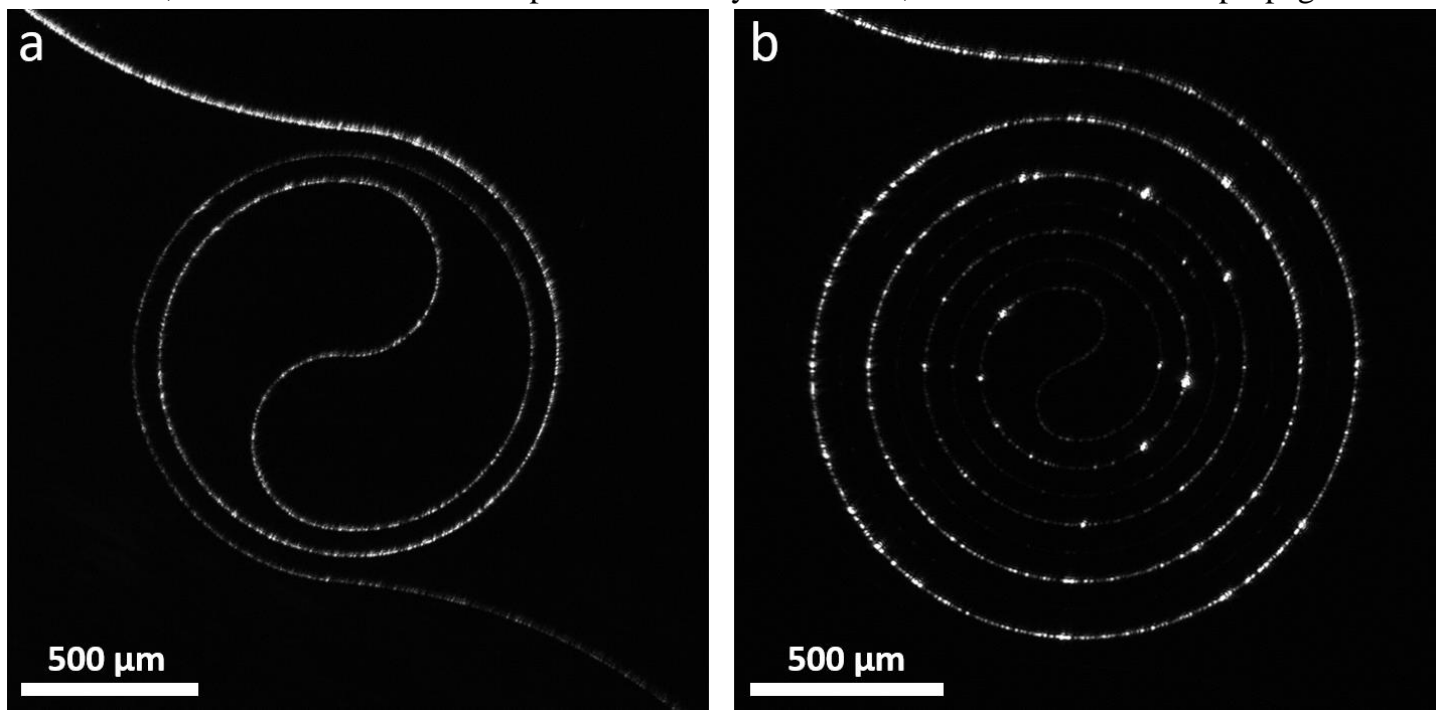

Figure 7. Topview image of the scattered light at a wavelength of $632.8 \mathrm{~nm}$ for (a) waveguide A and (b) waveguide B.

The resulting intensity trace and corresponding exponential fit are shown in figure 8 . The calculated losses from the exponential fit for waveguide A are $7.84 \pm 0.72 \mathrm{~dB} / \mathrm{cm}$ and for waveguide B $5.08 \pm 0.65 \mathrm{~dB} / \mathrm{cm}$. Where the error margin is obtained from the standard deviation of the fit parameters. 

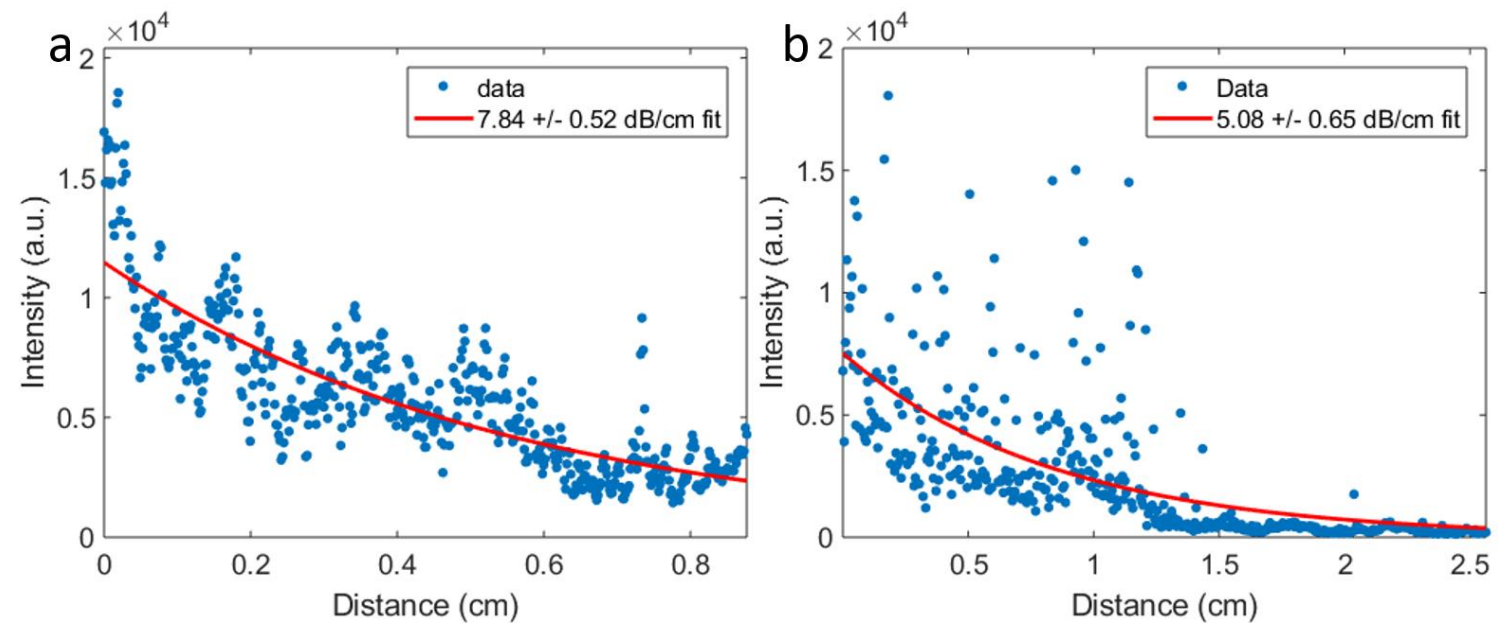

Figure 8. Exponential fit to the intensity profile of the scattered light of (a) waveguide A and (b) waveguide B, resulting in losses, at a wavelength of $632.8 \mathrm{~nm}$. of $7.84 \mathrm{~dB} / \mathrm{cm}$ and $5.08 \mathrm{~dB} / \mathrm{cm}$ respectively.

Optimization of the deposition, lithography and etching processes resulted in, to our knowledge, the lowest propagation losses in $\mathrm{TiO}_{2}$ channel waveguides compared to those shown in literature. Even lower losses can be expected after depositing an $\mathrm{SiO}_{2}$ cladding, since this reduces the refractive index contrast between the core and cladding, which reduces the scattering losses due to surface and sidewall roughness.

\section{CONCLUSION}

The deposition, lithography and etching processes for the fabrication of $\mathrm{TiO}_{2}$ channel waveguides were optimized. The DC reactive sputter deposition process was modified in order to take hysteresis out of the process. This was done by increasing the gas flow of $\mathrm{Ar}$ and $\mathrm{O}_{2}$ into the reactor. The hysteresis free process allowed to deposit layers at a process configuration, that could not be reached in a process with hysteresis. This resulted in $\mathrm{TiO}_{2}$ thin films with significantly lower propagation losses. An E-beam lithography process was developed using negative E-beam resist, in order to obtain resist patterns with high resolution, to reduce the sidewall roughness of the channel waveguide. The etching was performed by reactive ion etching. Different chemistries were compared, which showed $\mathrm{BCl}_{3}$ to be the most beneficial for etching with high selectivity towards resist. The etch rate and selectivity was improved by increasing the $\mathrm{BCl}_{3}$ flow and adding $\mathrm{HBr}$ to the process. This resulted in an etching recipe with a selectivity of 2.7 of $\mathrm{TiO}_{2}$ towards the E-beam resist, where the etching using $\mathrm{SF}_{6}$ showed a selectivity of approximately 0.2 . Waveguides were fabricated with the process before and after optimization. The channel waveguide before optimization showed propagation losses of $7.84 \pm 0.52 \mathrm{~dB} / \mathrm{cm}$ at a wavelength of $632.8 \mathrm{~nm}$, after applying an $\mathrm{SiO}_{2}$ top cladding by evaporation. The channel waveguide after optimization of all process steps showed losses of $5.08 \pm 0.65 \mathrm{~dB} / \mathrm{cm}$, also at a wavelength of $632.8 \mathrm{~nm}$, without applying a top cladding. Lower losses are to be expected after covering the waveguide with an $\mathrm{SiO}_{2}$ cladding.

\section{ACKNOWLEDGEMENT}

Mike Dikkers of the MESA+ cleanroom staff is acknowledged for his support and useful discussions regarding the optimization of the sputter deposition process. René Heideman, from LioniX International, is also acknowledged for his input and useful discussions regarding the optimization process.

\section{FUNDING}

This work is part of the research programme Industrial Doctorates with project number NWA.ID.17.100, which is financed by the Dutch Research Council (NWO).

\section{REFERENCES}

1. M. Furuhashi, M. Fujiwara, T. Ohshiro, M. Tsutsui, K. Matsubara, M. Taniguchi, S. Takeuchi, and T. Kawai, "Development of microfabricated $\mathrm{TiO}_{2}$ channel waveguides," AIP Adv. 1, 032102 (2011). 
2. J. D. B. Bradley, C. C. Evans, J. T. Choy, O. Reshef, P. B. Deotare, F. Parsy, K. C. Phillips, M. Lončar, and E. Mazur, "Submicrometer-wide amorphous and polycrystalline anatase $\mathrm{TiO}_{2}$ waveguides for microphotonic devices," Opt. Express 20, 23821-23831 (2012).

3. M. Landmann, E. Rauls, and W. G. Schmidt, "The electronic structure and optical response of rutile, anatase and brookite TiO 2," J. Phys. Condens. Matter 24, 195503 (2012).

4. R. Ronchin, A. Chiasera, M. Montagna, R. Rolli, C. Tosello, and E. Al., "Erbium-activated silica-titania planar and channel waveguides prepared by rf-sputtering," in SPIE (2001), Vol. 4282, p. 38.

5. T. Kornher, K. Xia, R. Kolesov, B. Villa, S. Lasse, C. S. Sandu, E. Wagner, S. Harada, G. Benvenuti, H. W. Becker, and J. Wrachtrup, "Amorphous Silicon-Doped Titania Films for on-Chip Photonics," ACS Photonics 4, 1101-1107 (2017).

6. A. Bahtat, M. Bouderbala, M. Bahtat, M. Bouazaoui, J. Mugnier, and M. Druetta, "Structural characterisation of Er3+ doped sol-gel $\mathrm{TiO}_{2}$ planar optical waveguides," Thin Solid Films 323, 59-62 (1998).

7. A. Bahtat, M. Bouazaoui, M. Bahtat, C. Garapon, B. Jacquier, and J. Mugnier, "Up-conversion fluorescence spectroscopy in Er3+: $\mathrm{TiO}_{2}$ planar waveguides prepared by a sol-gel process," J. Non. Cryst. Solids 202, 16-22 (1996).

8. C. C. Evans, K. Shtyrkova, O. Reshef, M. Moebius, J. D. B. Bradley, S. Griesse-Nascimento, E. Ippen, and E. Mazur, "Multimode phase-matched third-harmonic generation in sub-micrometer-wide anatase $\mathrm{TiO}_{2}$ waveguides," Opt. Express 23, 7832-7841 (2015).

9. K. Hammani, L. Markey, M. Lamy, B. Kibler, J. Arocas, J. Fatome, A. Dereux, J.-C. Weeber, and C. Finot, "Octave Spanning Supercontinuum in Titanium Dioxide Waveguides," Appl. Sci. 8, 543 (2018).

10. C. C. Evans, K. Shtyrkova, J. D. B. Bradley, O. Reshef, E. Ippen, and E. Mazur, "Spectral broadening in anatase titanium dioxide waveguides at telecommunication and near-visible wavelengths," Opt. Express 21, 18582 (2013).

11. X. Guan, H. Hu, L. K. Oxenløwe, and L. H. Frandsen, "Compact titanium dioxide waveguides with high nonlinearity at telecommunication wavelengths," Opt. Express 26, 1055-1063 (2018).

12. O. Reshef, K. Shtyrkova, M. G. Moebius, S. Griesse-Nascimento, S. Spector, C. C. Evans, E. Ippen, and E. Mazur, "Polycrystalline anatase titanium dioxide microring resonators with negative thermo-optic coefficient," J. Opt. Soc. Am. B 32, 2288-2293 (2015).

13. L. He, Y. Guo, Z. Han, K. Wada, L. C. Kimerling, J. Michel, A. M. Agarwal, G. Li, and L. Zhang, "Broadband athermal waveguides and devices for datacom and telecom applications," in Proceedings of SPIE - The International Society for Optical Engineering (2018), Vol. 10537.

14. J. Bovington, R. Wu, K.-T. Cheng, and J. E. Bowers, "Thermal stress implications in athermal $\mathrm{TiO}_{2}$ waveguides on a silicon substrate," Opt. Express 22, 661-666 (2014).

15. F. Qiu, A. M. Spring, and S. Yokoyama, "Athermal and high-Q hybrid $\mathrm{TiO}_{2}-\mathrm{Si}_{3} \mathrm{~N}_{4}$ ring resonator via an etchingfree fabrication technique," ACS Photonics 2, 405-409 (2015).

16. B. Guha, J. Cardenas, and M. Lipson, "Athermal silicon microring resonators with titanium oxide cladding," Opt. Express 21, 26557-26563 (2013).

17. S. S. Djordjevic, J. Basak, B. Guan, K. Shang, H.-F. Liu, S. T. S. Cheung, L. Liao, and S. J. B. Yoo, "CMOScompatible, athermal silicon ring modulators clad with titanium dioxide," Opt. Express 21, 13958 (2013).

18. A. Dhakal, A. Z. Subramanian, P. Wuytens, F. Peyskens, N. Le Thomas, and R. Baets, "Evanescent excitation and collection of spontaneous Raman spectra using silicon nitride nanophotonic waveguides," Opt. Lett. 39, 4025-4028 (2014).

19. C. C. Evans, C. Liu, and J. Suntivich, "TiO ${ }_{2}$ Nanophotonic Sensors for Efficient Integrated Evanescent Raman Spectroscopy," ACS Photonics 3, 1662-1669 (2016).

20. C. C. Evans, C. Liu, and J. Suntivich, "Low-loss titanium dioxide waveguides and resonators using a dielectric lift-off fabrication process," Opt. Express 23, 11160-1169 (2015).

21. J. D. B. Bradley, C. C. Evans, F. Parsy, K. C. Phillips, R. Senaratne, E. Marti, and E. Mazur, "Low-loss $\mathrm{TiO}_{2}$ planar waveguides for nanophotonic applications," in 2010 IEEE Photinic Society's 23rd Annual Meeting (IEEE, 2010), pp. 313-314.

22. L. Jiang, C. C. Evans, O. Reshef, and E. Mazur, "Optimizing anatase- $\mathrm{TiO}_{2}$ deposition for low-loss planar waveguides," in Proc. of SPIE (2013).

23. M. Lamy, C. Finot, J. Fatome, J. Arocas, and J. C. Weeber, "Demonstration of High-Speed Optical Transmission at $2 \mu \mathrm{m}$ in Titanium Dioxide Waveguides," Appl. Sci. 7, 631 (2017).

24. S. Berg and T. Nyberg, "Fundamental understanding and modeling of reactive sputtering processes," Thin Solid 
Films 476, 215-230 (2005).

25. M. Hayrinen, M. Roussey, V. Gandhi, P. Stenberg, A. Saynatjoki, L. Karvonen, M. Kuittinen, and S. Honkanen, "Low-loss titanium dioxide strip waveguides fabricated by atomic layer deposition," J. Light. Technol. 32, 208212 (2014).

26. K. R. Choi, J. C. Woo, Y. H. Joo, Y. S. Chun, and C. Il Kim, "The dry etching characteristics of TiO 2 thin films in N2/CF4/Ar plasma," Trans. Electr. Electron. Mater. 15, 32-36 (2014).

27. I. Hotovy, S. Hascik, M. Gregor, V. Rehacek, M. Predanocy, and A. Plecenik, "Dry etching characteristics of $\mathrm{TiO}_{2}$ thin films using inductively coupled plasma for gas sensing," Vacuum 107, 20-22 (2014).

28. R. Adzhri, M. K. M. Arshad, M. F. M. Fathil, U. Hashim, A. R. Ruslinda, R. M. Ayub, S. C. B. Gopinath, C. H. Voon, K. L. Foo, M. N. M. Nuzaihan, A. H. Azman, and M. Zaki, "Reactive Ion etching of $\mathrm{TiO}_{2}$ thin film: The impact of different gaseous," RSM 2015 - 2015 IEEE Reg. Symp. Micro Nano Electron. Proc. 1-4 (2015).

29. S. Norasetthekul, P. Y. Park, K. H. Baik, K. P. Lee, J. H. Shin, B. S. Jeong, V. Shishodia, E. S. Lambers, D. P. Norton, and S. J. Pearton, "Dry etch chemistries for $\mathrm{TiO}_{2}$ thin films," Appl. Surf. Sci. 185, 27-33 (2001).

30. D. Kim, A. Efremov, H. Jang, S. Kang, S. J. Yun, and K.-H. Kwon, "Etching characteristics and mechanisms of $\mathrm{TiO}_{2}$ thin films in $\mathrm{HBr} / \mathrm{Cl} 2 / \mathrm{Ar}$ inductively coupled plasma," Jpn. J. Appl. Phys. 51, (2012).

31. J. C. Woo, Y. S. Chun, Y. H. Joo, and C. I. Kim, "The dry etching property of $\mathrm{TiO}_{2}$ thin films using metalinsulator-metal capacitor in inductively coupled plasma system," Vacuum 86, 2152-2157 (2012).

32. D. Depla, S. Heirwegh, S. Mahieu, J. Haemers, R. De Gryse, D. Depla, S. Heirwegh, S. Mahieu, J. Haemers, and R. De Gryse, "Understanding the discharge voltage behavior during reactive sputtering of oxides," J. Appl. Phys. 101, 013301 (2007).

33. I. Hegeman, M. Dijkstra, F. B. Segerink, W. Lee, and S. M. Garcia-Blanco, "Development of low-loss TiO2 waveguides," Opt. Express, in-press.

34. E. Särhammar, T. Nyberg, and S. Berg, "Applying "the upgraded Berg model" to predict hysteresis free reactive sputtering," Surf. Coatings Technol. 279, 34-38 (2015).

35. Titanium tetrachloride, ICSC No. 1230, International Labour Organization, https://www.ilo.org/dyn/icsc/showcard.display?p_card_id=1230\&p_edit=\&p_version=2\&p_lang=en (accessed Jan. 13, 2020)

36. E. H. Hall, J. M. Blocher, and I. E. Campbell, "Vapor Pressure of Titanium Tetrafluoride," J. Electrochem. Soc. 105, 275-278 (1958).

37. J. D. B. Bradley, F. Ay, K. Wörhoff, and M. Pollnau, "Fabrication of low-loss channel waveguides in $\mathrm{Al}_{2} \mathrm{O}_{3}$ and $\mathrm{Y}_{2} \mathrm{O}_{3}$ layers by inductively coupled plasma reactive ion etching," Appl. Phys. B Lasers Opt. 89, 311-318 (2007). 